\title{
Oral misoprostol solution in comparison to vaginal misoprostol for induction of labour in a randomized controlled trial
}

\author{
Ahmed M. Abbas*, Peter R. Thabet, Amgad E. Abou Gamrah, Osama S. El-Kady
}

Department of Obstetrics and Gynecology, Faculty of Medicine, Ain Shams University, Cairo, Egypt

Received: 14 July 2020

Accepted: 07 August 2020

\section{*Correspondence:}

Dr. Ahmed M. Abbas,

E-mail: ahmedmams@hotmail.com

Copyright: (c) the author(s), publisher and licensee Medip Academy. This is an open-access article distributed under the terms of the Creative Commons Attribution Non-Commercial License, which permits unrestricted non-commercial use, distribution, and reproduction in any medium, provided the original work is properly cited.

\begin{abstract}
Background: With more than $15 \%$ of all gravid women requiring prostaglandins in cervical ripening and labour induction. However, evidence is not clear about the preferred route or dose of the drug. So, this study was designed with objectives to compare the induction delivery interval and safety of titrated oral misoprostol solution with vaginal misoprostol for labour induction in term primigravida women.

Methods: This randomized controlled clinical trial was conducted on a total of 100 patients randomly selected among primigravida at term women undergoing induction of labour for obstetric or medical indication for labour induction in Ain Shams University Maternity Hospital. They were divided into two Groups: Group I: patients undergoing induction of labour using misoprostol oral solution and Group II: patients undergoing induction of labour using vaginal misoprostol.

Results: Oral misoprostol solution has less induction delivery duration and less side effects than vaginal misoprostol. The induction-delivery time with the oral route compared to the vaginal one (15.2 versus 20.3 hours respectively) with significant p-value $(<0.001)$.

Conclusions: Titrated oral misoprostol is safe and effective for labour induction in primigravida patients with unfavorable cervix.
\end{abstract}

Keywords: Induction of labour, Oral, Vaginal misoprostol

\section{INTRODUCTION}

Induction of labour after completing 36 weeks gestation is a common obstetric intervention. Induction of labour is known as the artificial initiation of labour before its natural start for the safety of the mother, fetous or both of them using mechanical or pharmacological methods. ${ }^{1}$ In developing countries, finding a cheap and available option for induction of labour is of at most importance. ${ }^{2}$ Misoprostol, a synthetic prostaglandin E1 analogue, presents one of optimal options that has been widely used. $^{3}$

Misoprostol is a unique prostaglandin E1 analogue. Tablets, was at first introduced as treatment of gastric ulceration induced by anti-inflammatory drug. Since that, the use of misoprostol has been reviewed in pregnancy. ${ }^{4}$ Introduction of misoprostol was done by Sanchez-Ramos et al. ${ }^{5}$ Several randomized trials of labour with misoprostol have been undertaken. ${ }^{6-12}$

Misoprostol has advantages of being easy to use, various routes administration like the vaginal, sublingual and oral and having a longer shelf life. ${ }^{13}$

Misoprostol could be one of the best options for labour induction, as titrated low-dose oral solution seems to be the safest in terms of caesarean section risk, while vaginal misoprostol tablets are the most effective in achieving vaginal delivery within 24 hours of induction. ${ }^{14}$ Since 1992 as published in the article of Margulies et al and the initial American clinical report by Sanchez-Ramos et al 
detailing the use of misoprostol for cervical ripening and labour induction, there has been growing interest in this agent. $^{15}$

\section{METHODS}

This randomized controlled trial was conducted in the department of obstetrics and gynecology at Ain Shams University Maternity Hospital.

\section{Two groups were made}

Group I: patients undergoing induction of labour using misoprostol oral solution (prepared a1 tablet of 200 microgram dissolved in $200 \mathrm{ml}$ of drinking water used as $20 \mathrm{ml} /$ hour).

Group II: patients undergoing induction of labour using vaginal misoprostol 25 microgram 4 hourly.

Patients recruited in the study were primigravida at term with obstetric or medical indication for labour induction. These patients were either booked attending antenatal clinic referred for induction of labour or emergency admissions in labour room.

A total of 100 women were randomly selected for the study. The method of induction of labour was explained to patients, and only those who gave consent were finally selected for the study.

\section{Inclusion criteria}

The study included primigravida or primipara, pregnancy between 36 and 42 weeks of gestation, a live singleton fetus in cephalic presentation, no history of uterine surgery, clinically adequate pelvis, modified Bishop's score $<5$ and reactive non-stress test (NST).

\section{Exclusion criteria}

While known hypersensitivity or contraindications to oral misoprostol (uterine surgery). Any antenatal medical complications. A situation requiring LSCS (maternal or fetal) e.g.: fetal distress, non-reactive NST or patient's refusal to give consent were excluded from the study.

One hundred opaque envelopes were numbered serially and, in each envelope, the corresponding letter which denotes the allocated group was put according to randomization table. Then all envelopes were closed and put in one box. When the first patient arrives, the first envelope was opened and the patient was allocated according to the letter inside. Randomization of patients was done using a computerized program (SPSS). Sealed envelopes were numbered according to the randomization tables. Packing, sealing and numbering of the envelope was performed by neutral medical personnel (under the supervision of doctors from the department of obstetrics and gynecological).
Women of Group I was given $20 \mathrm{ml}(20 \mu \mathrm{g})$ of misoprostol solution orally every 2 hourly until adequate uterine contractions occurred ( 3 contractions per $10 \mathrm{~min}$ lasting 30-40 s). To overcome the problem of breaking the $200 \mu \mathrm{g}$ tablet of misotec into small fragments, authors dissolved the tablet in $200 \mathrm{ml}$ of water $(1 \mu \mathrm{g}$ per $\mathrm{ml})$ shaking the solution well before each administration. Thus, exact $20 \mu \mathrm{g}$ of misoprostol solution could be administered. Storage of solution was done at room temperature for max 24 hours in a glass bottle. The timing and strength of uterine contractions were assessed by regular abdominal palpation. Fetal heart rate and uterine activity were continuously monitored by electronic fetal heart rate monitor. Temperature, pulse, blood pressure, and occurrence of any side effects of the drug monitored/4 hours. Patients reassessed every 2 hourly for adequate uterine contractions (3 contractions for every $10 \mathrm{~min}$ lasting for 30-40s). Repeat $20 \mu \mathrm{g}$ oral misoprostol solution was given. Modified Bishop's score was assessed at 6 hours after the first dose, and whether it remained unchanged or increased to 5 or more than 5 was noted. In case of Bishop's score, less than 5 repeat misoprostol solution doses was given.

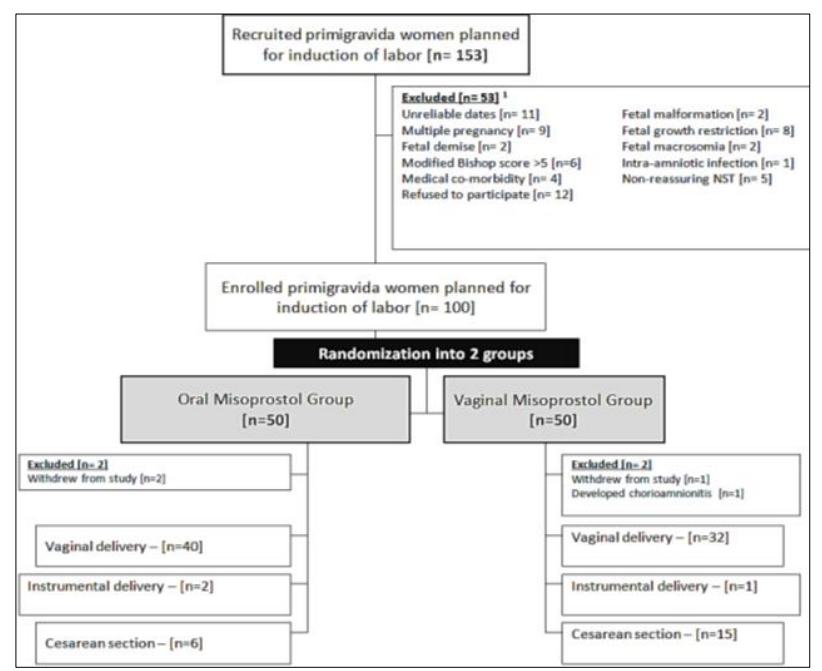

Figure 1: CONSORT 2010, the recruitment and handling of the study population during the course of the study.

It should be noted the considerable overlap in the causes of exclusion in the recruited women, e.g. some women were excluded due to both unreliable dates and medical co-morbidity. ${ }^{1}$

The induction regimen of Group II included application of misoprostol $25 \mu \mathrm{g}$ tablet in the posterior fornix of the vagina every 4 hours (up to 6 doses) after determination of the Bishop score. In case of adequate uterine contractions, per vaginal examination was done. The cervix was defined as favorable if cervical dilatation was $>4 \mathrm{~cm}$ with $30 \%$ effacement. In patients with favorable cervix, amniotomy was done, colour of liquor was observed, and WHO partograph was plotted. Further doses of misoprostol were not administered to these patients and progress of labour was observed as they entered the active phase of labour. If subsequent 
contractions become inadequate $(<3$ contraction in 10 min lasting for $<20 \mathrm{~s}$.) or no progress of labour for 2 hours on partograph, those patients started with oxytocin administration. Timing of oxytocin administration was noted. Progress of labour was monitored. Any drug reaction or side effect will be noted. If a woman was not in active phase of labour after receiving 10 doses of misoprostol solution or failed to deliver within 24 hours after initial administration of misoprostol, patients who required LSCS for failure to progress will be categorized as failed induction. Women who delivered vaginally within 24 hours from initial administration of misoprostol will be considered as successful induction.

\section{Statistical methods}

\section{Sample size justification}

MedCalc ${ }^{\circledR}$ version 12.3.0.0 program was used for calculations of sample size, statistical calculator based on 95\% confidence interval and power of the study $80 \%$ with $\alpha$ error 5\%, According to a previous study (16), showed that the vaginal delivery $<12$ hours $(50.9 \%$ versus $21.8 \%$ ) comparing oral misoprostol solution versus vaginal misoprostol respectively, with $\mathrm{p}$-value ( $<0.001$ highly significant). So, it can be relied upon in this study, based on this assumption, sample size was calculated according to these values produced a minimal samples size of 96 cases were enough to find such a difference. Assuming a drop-out ratio of 5\%, the sample size will be 50 women in each group.

\section{Statistical analysis}

The collected data were tabulated, and statistically analyzed using SPSS program (statistical package for social sciences) software version 20.0. Descriptive statistics were done for numerical parametric data as mean \pm SD (standard deviation) and minimum and maximum of the range and for numerical non parametric data as median and $1^{\text {st }}$ and $3^{\text {rd }}$ inter-quartile range, while they were done for categorical data as number and percentage. Inferential analyses were done for quantitative variables using independent t-test in cases of two independent groups with parametric data and Mann Whitney $U$ in cases of two independent groups with nonparametric data. Inferential analysis was done for qualitative data using Chi square test for independent groups. The level of significance was taken at $p$ value $<0.050$ is significant, otherwise is non-significant. The pvalue is a statistical measure for the probability that the results observed in a study could have occurred by chance.

\section{RESULTS}

A total 153 study subjects assessed for eligibility to be recruited for the research study either booked or on casual admission, after good history taking 53 of them were excluded from the research as 41 didn't meet the inclusion research criteria 12 of them refused to participate. 100 study subjects remaining were categorized in two research groups 50 cases in each the oral misoprostol research group and the vaginal misoprostol research group. Two women from the oral misoprostol were withdrawn from the study, while 3 were excluded from the other group; 2 withdrawn and one developed chorioamniotis.

There was no statistically significant difference between oral and vaginal research groups as regards basal maternal characteristics (age, BMI, bishop score $\mathrm{p}$ values $=0.57,0.790,0.11$, consecutively) and fetal characteristics (GA, expected fetal weight, $p$ values $=059$, 0.16 , consecutively) and indications of induction ( $p$ value $=0.43$ ).

Failed induction of labor occurred in two patients in the oral misoprostol group and five patients in the vaginal misoprostol group, yielding a success rate of $95.83 \%$ and $89.58 \%$ respectively. No statistically significant difference was found on comparing the success rate in the two study groups with an estimated relative risk of failed induction of 1.06 (95\% CI 0.95-1.19). Number needed to treat was estimated to be 16 , i.e., 16 patients should have labor induced using the oral route rather than the vaginal route; in order to avoid an additional single failure of the vaginal route.

Table 1: Comparison between the study groups regarding demographic and clinical characteristics.

\begin{tabular}{|lll|}
\hline & Oral misoprostol group & Vaginal misoprostol group \\
\hline Age (years) & $24.6 \pm 2.80$ & $25.0 \pm 2.93$ \\
\hline BMI (kg/m $\mathbf{m}^{2}$ ) & $24.20 \pm 1.55$ & $24.28 \pm 1.62$ \\
\hline Gestational age (weeks) & $41.0(39.0-41.0)$ & $41.0(38.5-41.0)$ \\
\hline EFW (kg) & $3.30(2.75-3.40)$ & $3.20(2.70-3.35)$ \\
\hline Pre-induction Bishop score & $4(4-4)$ & $4(3-4)$ \\
\hline Indication for induction of labor & & \\
\hline Post-term & $32(66.7)$ & $26(54.2)$ \\
\hline Pre-labor ROMs & $11(22.9)$ & $14(29.2)$ \\
\hline Oligohydramnios & $5(10.4)$ & $8(16.7)$ \\
\hline
\end{tabular}


Table 2: Comparison between study groups regarding success rate of induction of labor.

\begin{tabular}{|c|c|c|c|}
\hline & $\begin{array}{l}\text { Oral misoprostol } \\
\text { group }\end{array}$ & $\begin{array}{l}\text { Vaginal misoprostol } \\
\text { group }\end{array}$ & $P$ value \\
\hline Total dose of misoprostol ( $\mu \mathrm{gm})$ & $60.0(60.0-80.0)$ & $50.0(50.0-50.0)$ & $<0.001$ \\
\hline Difference between medians $(95 \% \mathrm{CI})$ & $10.0(10.0-10.0)$ & & \\
\hline Need for augmentation by oxytocin (\%) & $11(23.9)$ & $15(34.9)$ & 0.35 \\
\hline Maximum dose of oxytocin required (mIU) & $9.45 \pm 3.69$ & $11.73 \pm 4.65$ & 0.19 \\
\hline Successful induction of labor & $46(95.83)$ & $43(89.58)$ & 0.43 \\
\hline Relative risk $(95 \% \mathrm{CI})$ & $0.40(0.08-1.96)$ & & \\
\hline Induction-active phase interval & $10.70(10.40-11.40)$ & $14.30(13.80-15.0)$ & $<0.001$ \\
\hline Hazard ratio $(95 \% \mathrm{CI})$ & $3.23(1.99-5.22)$ & & \\
\hline Induction-delivery interval & $15.20(14.90-16.60)$ & $20.30(19.40-21.1)$ & $<0.001$ \\
\hline Hazard ratio $(95 \% \mathrm{CI})$ & $3.67(2.16-6.25)$ & & \\
\hline \multicolumn{4}{|l|}{ Mode of delivery } \\
\hline Unassisted vaginal delivery & $40(83.3)$ & $32(66.7)$ & \multirow{9}{*}{0.07} \\
\hline Assisted vaginal delivery & $2(4.2)$ & $1(2.1)$ & \\
\hline Fetal distress & $1(50)$ & $1(100)$ & \\
\hline Arrest of labor & $1(50)$ & $0(0)$ & \\
\hline Caesarean section & $6(12.5)$ & $15(31.2)$ & \\
\hline Fetal distress & $2(33.3)$ & $4(26.6)$ & \\
\hline Arrest of labor & $2(33.3)$ & $5(33.3)$ & \\
\hline Failed induction & $2(33.3)$ & $5(33.1)$ & \\
\hline Others & $0(0)$ & $1(6.7)$ & \\
\hline \multicolumn{4}{|l|}{ Neonatal outcomes } \\
\hline EBW $(\mathrm{kg})$ & $3.30(2.75-3.40)$ & $3.20(2.70-3.35)$ & 0.16 \\
\hline 1-min Apgar score & $7(7-7.5)$ & $7(7-7)$ & 0.32 \\
\hline 5-min Apgar score & $8(8-8.5)$ & $8(8-8)$ & 0.62 \\
\hline NICU admission (\%) & $2(4.2)$ & $3(6.2)$ & 1.0 \\
\hline Stillbirth & $0(0)$ & $0(0)$ & - \\
\hline
\end{tabular}

Table 3: Comparison between the study groups regarding need for intervention.

\begin{tabular}{|c|c|c|c|}
\hline & $\begin{array}{l}\text { Oral misoprostol } \\
\text { group }(\%)\end{array}$ & $\begin{array}{l}\text { Vaginal misoprostol } \\
\text { group }(\%)\end{array}$ & $\begin{array}{l}P \\
\text { value }\end{array}$ \\
\hline \multicolumn{3}{|l|}{ Intervention rate } & \multirow{4}{*}{0.24} \\
\hline Total intervention & $8(16.7)$ & $16(33.3)$ & \\
\hline Assisted vaginal delivery & $2(4.2)$ & $1(2.1)$ & \\
\hline Caesarean section & $6(12.5)$ & $15(31.2)$ & \\
\hline \multicolumn{3}{|l|}{ Indication for intervention } & \multirow{7}{*}{0.87} \\
\hline Fetal distress & $3(37.5)$ & $5(31.2)$ & \\
\hline $\begin{array}{l}\text { Acute bradycardia or single prolonged deceleration lasting } 3 \\
\text { minutes or more }\end{array}$ & $0(0)$ & $1(20.0)$ & \\
\hline Failure of conservative measures for pathological CTG & $3(100)$ & $4(80.0)$ & \\
\hline Arrest of labor & $3(37.5)$ & $5(31.2)$ & \\
\hline Failed induction & $2(25.0)$ & $5(31.2)$ & \\
\hline Others & $0(0)$ & $1(6.25)$ & \\
\hline
\end{tabular}

Kaplan-Meier analysis of induction-active phase interval revealed a statistically significantly shorter induction time with the oral route compared to the vaginal one (10.7 versus 14.3 hours respectively). Hazard ratio was calculated as 3.23 , i.e., at any given time, the probability of successful induction of labor with oral misoprostol is approximately thrice that with the vaginal route.
No statistically significant differences were found between both groups regarding the incidence of meconium-stained liquor or the different fetal heart rate abnormalities, i.e., basal heart rate, variability and decelerations. Relative risk for need of intervention with the oral route compared to the vaginal route was calculated to be 0.50 , i.e., risk for need of intervention 
using oral misoprostol was half that of the vaginal route. However, this finding lacked statistical significance. Number needed to treat was calculated to be 6.0 ; which means that on average 6 patients should receive misoprostol orally rather than vaginally in order to prevent an additional need for intervention.

Table 4: Risk analysis for need for intervention with oral route compared to the vaginal one.

\begin{tabular}{|ll|}
\hline Risk analysis & \\
\hline Relative risk (RR) & 0.50 \\
\hline $95 \%$ CI & $0.23-1.05$ \\
\hline P value & 0.06 \\
\hline $\begin{array}{l}\text { Number needed to } \\
\text { treat (benefit) }\end{array}$ & 6.0 \\
\hline $95 \%$ CI & 299.7 (harm) to $\infty$ to 2.9 (benefit) \\
\hline
\end{tabular}

Kaplan-Meier analysis of induction-delivery interval revealed a statistically significantly ( $p$ value $<0.001$ ) shorter induction-delivery time with the oral route compared to the vaginal one (15.2 versus 20.3 hours respectively). Hazard ratio was calculated as 3.67 , i.e., at any given time, the probability of successful unassisted vaginal delivery with oral misoprostol is approximately 3.5 times that with the vaginal route.

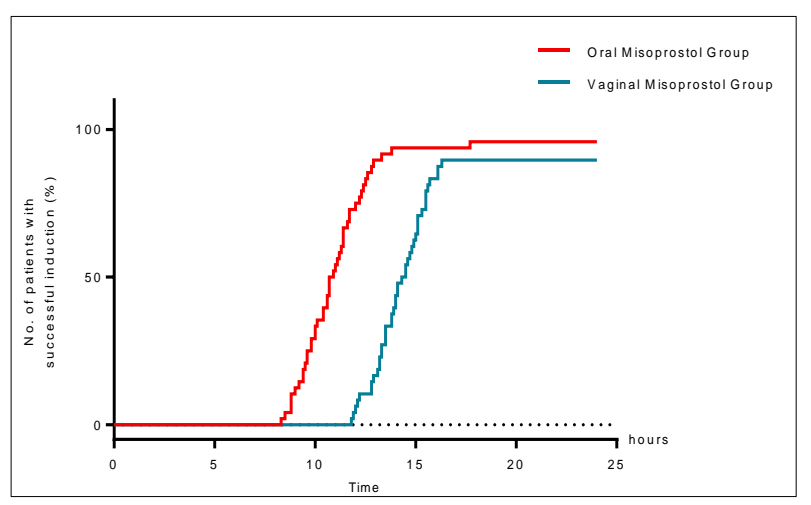

Figure 2: Kaplan-Meier analysis for time to active phase in oral and vaginal groups.

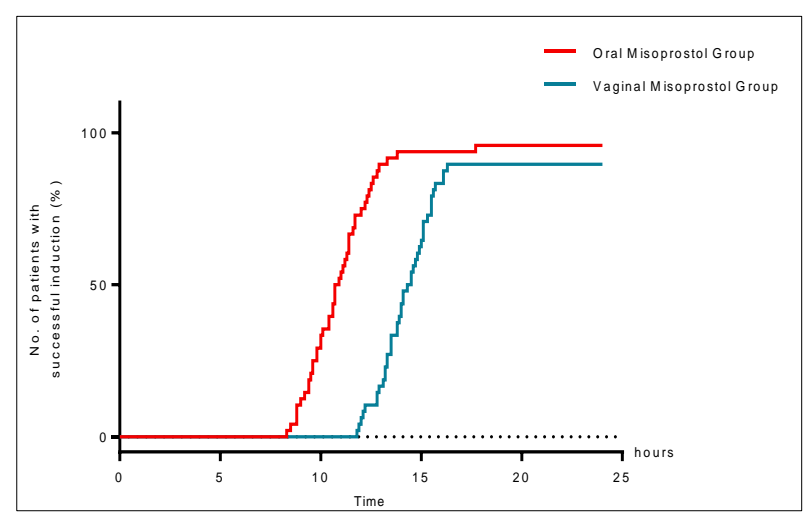

Figure 3: Kaplan-Meier analysis for time to active phase in oral and vaginal groups.
No statistically significant differences were found between both groups regarding the incidence of uterine hyperstimulation or fever. The incidence of nausea and vomiting was markedly higher with the oral route compared to the vaginal one; however, this relation failed to prove statistical significance.

\section{DISCUSSION}

Labour induction is basic, as well as, one of the most important obstetric procedures. It is indicated when the clinical benefits either maternally or fetally or for both outweigh the possible risks for continuation of pregnancy. $^{17}$

Ripening of the cervix by prostaglandin E1 (misoprostol) is well established, safe, consistent, low-cost procedure for induction of labour leading to well standardized clinical maternal and fetal outcomes. ${ }^{18}$

The ACOG recommends misoprostol as an efficient agent for cervical ripening and induction of labor at a dosage of $25 \mu \mathrm{g}$, administered intravaginally. However practitioners and researchers all over the globe/have been interested to investigate its usage via other routes such as oral and other dosages which is considered off the label usage mostly between 25 and $50 \mu \mathrm{g}$ dosages; on the other hand the active ingredient, instability is an issue that is still unresolved. ${ }^{19,20}$

Based on pharmacokinetics of misoprostol which is different for each route. For example, oral administration the onset of action is 8 minutes, T-max is 30 minutes and duration of action is 2 hours. For vaginal administration, the onset of action is 20 minutes, T-max is 70 minutes and duration of action is 4 hours, hence vaginal misoprostol remains effective for longer time and hence lesser dosage is required for induction of labour, assessment of routes of administration rather than vaginal route remain an area of research. ${ }^{24}$

The current research study was 153 study subjects assessed for eligibility to be recruited for the research study in which 53 of them were excluded from.100 study subjects remaining were categorized in two research groups 50 cases in each the oral misoprostol research group and the vaginal misoprostol research group. Of them 48 and 47 subjects were analyzed.

Failed induction of labor occurred in two patients in the oral misoprostol group and five patients in the vaginal misoprostol group, yielding a success rate of $95.83 \%$ and $89.58 \%$ respectively, with an estimated relative risk of failed induction of 1.06 (95\% CI 0.95-1.19), and number needed to treat was estimated to be 16 .

The primary outcome of this study was induction delivery time and it was significantly lower at Oral misoprostol group versus vaginal route group with 15.20 hours (14.90-16.60) and 20.30 hours (19.40-21.1) respectively 
having Hazard ratio (95\% CI) 3.67 (2.16-6.25). KaplanMeier analysis of induction-delivery interval revealed a statistically significantly ( $p$ value $<0.001)$ shorter induction-delivery time with the oral route compared to the vaginal one (15.2 versus 20.3 hours respectively). This was not in consistence with finding by many studies. $^{23-25}$ While Mahajan study in 2018 had the same finding as the current study. ${ }^{18}$ This could be explained as well as expected as different dosage regimen between these studies and this study. This could be proved by other studies comparing different dose regimens of oral misoprostol and different effect on induction delivery time and obstetric outcome. ${ }^{26,27}$

While total dose of misoprostol was significantly lower in vaginal misoprostol group in comparison to oral Misoprostol Group, $50 \mu \mathrm{gm}$ (50.0-50.0) $60.0 \mu \mathrm{gm}$ (60.0$80.0)$ but need for oxytocin augmentation and maximum dose of required oxytocin has no significant difference between both group and this is expected and could be explained by pharmacokinetics of misoprostol in different routes of administration. This was same conclusion made by Mahajan et al and Handal-Orefice et al agreed with this findings regarding oxytocin augmentation and dose, while Cheng in 2008 and Souza in 2013 reported a greater need for oxytocin in women using oral misoprostol $(57 \%)$ than in those with vaginal administration $(51 \%){ }^{18,24,27,28}$

Relative risk for need of intervention with the oral route compared to the vaginal route was calculated to be 0.50 , i.e., risk for need of intervention using oral misoprostol was half that of the vaginal route. However, this finding lacked statistical significance, so authors didn't find any statistically significant difference between both groups regarding rate of interventions, operative vaginal delivery or CS rate. and this was going hand in hand with many other studies. ${ }^{18,24,26,29,30}$ While two studies before found higher risk of CS with oral misoprostol but by looking more in depth this difference may be due to many points, Handal-Orefice study was retrospective, comparing both routs in different period of time and the studied group wasn't homogenous regarding many inclusion criteria like BMI. ${ }^{27,31}$

However, no statistically significant differences were found between both groups regarding the incidence of uterine hyperstimulation or fever. The incidence of nausea and vomiting was markedly higher with the oral route compared to the vaginal one; however, this relation failed to prove statistical significance. This wasn't the same as results of many studies revealing higher rate of Tachy systole with vaginal route of administration and again it may be expected with the understand of pharmacokinetics of misoprostol. ${ }^{24,26,27,32}$ While studies done by had no difference in occurrence of uterine tachysystole and by in depth read of all these studies authors could owe this difference in different dose used orally and its impact on induction delivery time as well as uterine tachysystole. ${ }^{25,30}$
The neonatal outcome at the end of the study was the same in both groups and this in consistent with many of the previous published data. ${ }^{24,25,28-31}$

\section{CONCLUSION}

Conclusion titrated orally administrated dose of misoprostol would be an effective method of induction of labor specially in our country Egypt with its cheap price and easily availability in comparison to different methods of induction of labor with no impact on obstetric and neonatal outcome.

\section{Funding: No funding sources Conflict of interest: None declared \\ Ethical approval: The study was approved by the Institutional Ethics Committee}

\section{REFERENCES}

1. Mackenzie IZ. Induction of labour at the start of the new millennium. Reprod. 2006;131(6):989-98.

2. Hofmeyr GJ, Gulmezoglu AM, Pileggi C. Vaginal misoprostol for cervical ripening and induction of labour. Cochrane Database Syst Rev. 2010;6:CD000941.

3. Deshmukh VL, Rajamanya AV, Yelikar KA. Oral misoprostol solution for induction of labour. J Obstet Gynaecol India. 2017;67(2):98-103.

4. Goldberg AB, Greenberg MB, Darney PD. Misoprostol and pregnancy. N Engl J Med. 2001;344:38-47.

5. Sanchez Ramos L, Kauritz AM, Del Valle GO. Labour induction with the prostaglandin. EL methyl analogue misoprostol versus oxytocin, a randomized trial. Obstet Gynaecol. 1993;81:332-6.

6. Tessier F, Dansereau J. A double-blind randomized controlled trial comparing oral misoprostol to vaginal prostaglandin E2 gel for the induction of labour at or near term. Am J Obstet Gynecol. 1997;176:S111.

7. Windrim R, Bennett K, Mundle W, Young DC. Oral administration of misoprostol for labour induction: a randomized controlled trial. Obstet Gynecol. 1997;89:392-7.

8. Adair CD, Weeks JW, Barrilleaux PS, Philibert L, Lewis DF. Labour induction with oral versus vaginal misoprostol: a randomized, double-blind trial. Am J Obstet Gynecol. 1998;178:S93.

9. Kwon JS, Davies GA, Mackenzie VP. A comparison of oral and vaginal misoprostol for induction of labour at term: a randomised trial. $\mathrm{Br} \mathrm{J}$ Obstet Gynecol. 2001;108:23-6.

10. Wing DA, Ham D, Paul RH. A comparison of orally administered misoprostol with vaginally administered misoprostol for cervical ripening and labour induction. Am J Obstet Gynecol. 1999; 180:1155-60.

11. Toppozada MK, Anwar MY, Hassan HA, ElGazaerly WS. Oral or vaginal misoprostol for 
induction of labour. Int $\mathbf{J}$ Gynecol Obstet. 1997;56:135-9.

12. Kadanali S, Küçüközkan T, Zor N, Kumtepe Y. Comparison of labor induction with misoprostol vs. oxytocin/prostaglandin E2 in term pregnancy. Int $\mathrm{J}$ Gynecol Obstet. 1996;55:99-104.

13. Antil S, Gupta U. Role of titrated low dose oral misoprostol solution in induction of labour. Int $\mathrm{J}$ Reprod Contracept Obstet Gynecol. 2016;5(3):77582.

14. Alfirevic Z, Keeney E, Dowswell T. Labour induction with prostaglandins: a systematic review and network meta-analysis. Am Coll Obstet Gynecol. 2015;350:g217.

15. Sanchez Ramos L, Kauritz AM, Del Valle GO. Labour induction with the prostaglandin. EL methyl analogue misoprostol versus oxytocin, a randomized trial. Obstet Gynaecol. 1993;81:332-6.

16. Induction of labour (CG70), 2008. Available at: www.nice.org.uk/CG70. Accessed on $12^{\text {th }}$ March 2020.

17. RCOG response to BMJ study on induction of labour, 2019. Available at: https://www.rcog.org.uk/en/news/rcog-response-tostudy-on-induction-of-labour-and-stillbirth-risk/ Accessed on $14^{\text {th }}$ March 2020.

18. Mahajan P, Popatrao R. Shitole comparison of titrated oral misoprostol solution versus vaginal misoprostol for induction of labour in term obstetric patients for obstetric and neonatal outcomes: a randomized controlled trial. Int J Reprod Contracept Obstet Gynecol. 2018;7(6):2339-46.

19. Leduc D, Biringer A, Lee L, Dy J. Induction of labour. J Obstet Gynaecol Can. 2013;35(9):840-57.

20. Osterman MJ, Martin JA. Recent declines in induction of labor by gestational age. NCHS Data Brief. 2014;155:1-8.

21. Alfirevic Z, Aflaifel N, Weeks A. Oral misoprostol for induction of labour. In: Weeks A, editor. The cochrane database of systematic reviews. Vol 6 . Chichester, UK: John Wiley and Sons, Ltd; 2014:CD001338.

22. Hofmeyr GJ, Gulmezoglu AM, Pileggi C. Vaginal misoprostol for cervical ripening and induction of labour. Cochrane Database Syst Rev. 2010;6:CD000941.

23. Hokkila E, Kruit H, Rahkonen L, Timonen S, Mattila M, Laatio L, et al. The efficacy of misoprostol vaginal insert compared with oral misoprostol in the induction of labor of nulliparous women: A randomized national multicenter trial. Acta Obstetricia et Gynecologica Scandinavica. 2019;98(8):1032-9.

24. Handal-Orefice RC, Friedman AM, Chouinard SM, Eke AC, Feinberg B, Politch J, et al. Oral or vaginal misoprostol for labor induction and cesarean delivery risk. Obstet Gynecol. 2019;134(1):10-6.

25. Redling K, Schaedelin S, Huhn EA, Hoesli I. Efficacy and safety of misoprostol vaginal insert vs. oral misoprostol for induction of labor. J Perinatal Med. 2018;47(2):176-82.

26. Rouzi AA, Alsahly N, Alamoudi R, Almansouri N, Alsinani N, Alkafy S, et al. Randomized clinical trial between hourly titrated and 2 hourly static oral misoprostol solution for induction of labor. Am J Obstet Gynecol. 2018;216(4):405.e1-405.e6.

27. Cheng SY, Ming H, Lee JC. Titrated oral compared with vaginal misoprostol for labour induction. Obstet Gynecol. 2008;111:119-25.

28. Souza ASR, Feitosa FEL, Costa AA, Pereira AP, Carvalho AS, Paixão RM, et al. Titrated oral misoprostol solution versus vaginal misoprostol for labor induction. Int J Gynecol Obstet. 2013;123:207.

29. Kafy S. Oral misoprostol 2 hourly for labor induction. Open J Obstet Gynecol. 2018;8(6):553-8.

30. Yousaf T, Asher Z, Afghan S, Malik K. Comparison of oral $(20 \mu \mathrm{g} 2$ hourly) versus vaginal $(25 \mu \mathrm{g} 6$ hourly) misoprostol for induction of labour in term pregnancies. Pak Armed Forces Med J. 2019;69(2):346-50.

31. Jindal P, Avasthi K, Kaur M. A comparison of vaginal vs. oral misoprostol for induction of labordouble blind randomized trial. J Obstet Gynaecol India. 2011;61:538-42.

32. Komala K, Reddy M, Quadri IJ. Comparative study of oral and vaginal misoprostol for induction of labour, maternal and foetal outcome. J Clin Diag Res. 2013;7(12):2866-9.

Cite this article as: Abbas AM, Thabet PR, Gamrah AEA, El-Kady OS. Oral misoprostol solution in comparison to vaginal misoprostol for induction of labour in a randomized controlled trial. Int J Reprod Contracept Obstet Gynecol 2020;9:3530-6. 